\title{
Lives on the line? Ethics and practicalities of duty of care in pandemics and disasters
}

\author{
A.K. Simonds* and D.K. Sokol ${ }^{\#}$
}

ABSTRACT: Pandemics and acute emergencies raise pressing medical, ethical and organisational challenges. These include global governance, priority setting, triaging of patients, allocation of scarce resources and restricting individual liberty in the interests of public health. We will focus particularly on an issue of direct relevance to all respiratory team members, i.e. what is the duty of the healthcare worker to continue working in the face of personal risk, and draw lessons from guidelines, ethical considerations, past pandemics and evolving experience with H1N1 swine influenza.

KEYWORDS: Avian influenza, duty of care, ethics, medical disasters, pandemic influenza, swine influenza

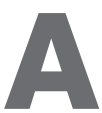
$\mathrm{n}$ influenza pandemic is an immediate global threat and governments across the world have instigated measures to deal with the arrival of the virus on their shores [1]. In Europe, as elsewhere, the level of preparedness varies from country to country $[2,3]$.

All epidemics of infectious disease raise ethical issues, from the restriction of individual liberty to triaging and resource allocation. In this article, we focus on an issue potentially affecting all healthcare workers: what are the duties of the healthcare worker in pandemics of virulent infectious disease? The severe acute respiratory syndrome (SARS) epidemics highlighted the relevance of this question to both pandemic preparedness plans and healthcare professionals. The locus of the disease was mainly healthcare facilities, and medical staff bore a significant brunt of the infection [4]. In Toronto, Canada, healthcare workers represented $40 \%$ of cases, and in Taiwan and Hong Kong 18\% and 25\% of cases, respectively, involved healthcare staff.

Although all hospital workers are exposed to some risk of infection, the extent of this risk is not distributed equally. Some specialties have always been subject to comparatively high risk. In pandemic flu, primary care and emergency room staff, and particularly respiratory and infectious diseases teams, critical care staff and anaesthesiologists, are likely to be at higher risk than those in unrelated or nonacute specialties. Nurses tend to spend more time in close contact with patients, and those carrying out aerosol-generating procedures may be at increased risk. The role of essential nonmedical domestic and cleaning staff, as well as catering team members and porters, should not be overlooked.

\section{RELEVANT ASSUMPTIONS, MISPERCEPTIONS AND UNKNOWNS}

Pandemic flu in humans will follow a mutation in the animal influenza virus reservoir that will facilitate human to human spread. This may reduce virulence, putting into question the assumption that pandemic flu will be as lethal as SARS. We simply do not know how virulent the virus will be in any pandemic. Press coverage is often alarmist ("killer/deadly bug") and media accounts rarely give prominence to public health recommendations, such as hand washing [5]. Conversely, cynicism and criticism of "medical hype" may be evident if initial cases are mild [6]. The 1957 and 1968 influenza epidemics in the UK were less severe than the 1918-1919 outbreak (1-4 million deaths combined compared with an estimated 20-40 million deaths worldwide). In the more recent influenza epidemics, deaths were predominantly in the elderly and the young [7]. In the SARS epidemics, deaths occurred in adults, but in cases of H5N1 avian flu (bird to human transfer) children and young adults are the main population will be disproportionately affected in the next flu pandemic. Familial avian flu cases suggest a genetic susceptibility to the virus. Many national pandemic flu preparedness plans are victims. It is not clear whether one section of the

\section{AFFILIATIONS}

${ }^{*}$ Clinical and Academic Unit of Sleep and Breathing, Royal Brompton \& Harefield NHS Trust, and

${ }^{\text {\#}}$ St George's Hospital Medical School, University of London, London, UK.

\section{CORRESPONDENCE}

A.K. Simonds

Clinical and Academic Unit of Sleep and Breathing

Royal Brompton \& Harefield NHS

Trust

London

SW3 6NP

UK

E-mail: A.Simonds@rbht.nhs.uk

Received:

March 142009

Accepted after revision:

May 062009 
working on the estimate of a pandemic influenza attack rate of up to $50 \%$, with $\sim 2.5 \%$ mortality. It is thought that $\sim 4 \%$ of those who are symptomatic will require hospital admission, and $25 \%$ of these will need intensive care if facilities are available. Clearly these figures can be revised if the virus proves less virulent and cases can be cared for in the community.

It is reasonable to assume that healthcare workers will have the same attack rate as the rest of the population. This is where pandemic flu diverges most from SARS, as while SARS had a hospital focus, the influenza virus is likely to be widespread in the community. These differences are explained by the shorter incubation time of the influenza virus, the likelihood of transmission earlier in the disease, and a higher transmission rate. Healthcare workers will inevitably be exposed to risk at work but, once the patient is diagnosed, suitable infection control precautions should lead to a considerable reduction in risk. In contrast, the risk of infection from the sneeze of a passer-by at the market place or on public transport is more difficult to quantify and counteract.

According to national plans [2], schools will close in order to slow the spread of the pandemic in most countries, with consequent childcare problems for staff with nursery or school age children. It is estimated that $30-50 \%$ of the healthcare workforce will be absent temporarily due to infection, quarantine, childcare, care of other dependants, or transport difficulties. This will put pressure on remaining team members and require diversification of work practices. This diversification will occur at trigger points. Elective surgery and admissions will cease, freeing up surgeons, anaesthesiologists, intensive care unit (ICU) bed space and equipment (e.g. operating theatre ventilators). Meanwhile, essential non-flu services, such as obstetric services, emergency surgery, psychiatry and community services will need to be maintained and an equitable balance struck between flu and non-flu work and acute and tertiary services, in terms of both staff and the allocation of resources.

\section{DUTY OF THE PROFESSIONAL}

In high-risk emergency situations, such as in epidemics or bioterrorist attacks, the doctor is subject to a number of competing duties: 1) a duty to patients; 2) a duty to protect oneself from undue risk of harm; 3) a duty to one's family; 4) a duty to colleagues whose workloads and risk of harm will increase in one's absence; and 5) a duty to society.

The very nature of being a clinician entails a duty of beneficence to patients. Hence, morally, doctors have greater obligations to help patients than nonclinicians. The profession as a whole also has an implicit contract with society (which has usually subsidised medical training) to provide medical help in times of crisis. This raises several questions: what is an acceptable level of risk to the healthcare professional? When does the risk cease to be reasonable, and who should decide [8]? Professional organisations offer some guidance. For example, the UK General Medical Council advises in Good Medical Practice [9]: "Doctors must not refuse to treat patients because their medical condition may put the doctor at risk. The balance between protecting individual doctors and their families from harm, and ensuring patients are not put at unnecessary risk, is best addressed at local level, taking into account the principle that those who place themselves at additional risk should be supported in doing so and the risks and burdens minimized as far as possible."

The American Medical Association (AMA) in its code of ethics adds a longer term perspective [10]: "Physicians should balance immediate benefits to individual patients with ability to care for patients in future."

For the AMA, the level of risk to be taken is left to the discretion of the individual, but it is noteworthy that the justification for not treating patients is one purely based on beneficence to future patients, not on the physician's other obligations to self or loved ones.

In exchange for their work, doctors receive benefits from society, including high status, public respect and some receive substantial financial reward. As mentioned earlier, some specialities are more exposed to risk than others, and rewards are higher in senior members of the profession, yet junior medics and nurses may be at greater risk of infection than senior staff due to more frequent exposure. The same applies to paramedics and community teams, who will care for sick patients outside the hospital. From a nursing perspective, most codes of ethics expect that nurses "should make the care of their patients their first concern". The UK Nursing and Medical Council states [11]: "Nurses have both a legal and professional duty of care. A court of law could find a nurse negligent if a person suffered harm because they neglected to care for them adequately."

The professional guidance above goes against the ethical analysis of one of the authors (D.K. Sokol), who has claimed that physicians' duty of care is not limitless, as purported by the professional governance authorities, but determined by various factors including the physician's speciality (hence an ophthalmologist and an infectious disease specialist accept different levels of risk), the burdens and risk of harm to the clinician, the likely benefit of treatment to patients, and the strength of other competing moral obligations brought about by the clinician's multiple roles (e.g. as parent, spouse or carer) [3].

Noting the emphasis in the literature on triage and resource allocation in a pandemic, MALM et al. [12] have focused their attention on human resources. While one strategy is to claim that healthcare workers have an absolute duty of care, however perilous the situation, the authors conclude that such an approach, although pleasingly simple, would deter individuals from entering the field. Instead, they propose a contract-based consent: healthcare workers should voluntarily acknowledge the duty to treat during a pandemic and should be remunerated for that responsibility.

While MALM et al. [12] urge changes in the employment contract, some national preparedness plans appear to favour flexible working and "special leave" agreements between staff and management to cover pandemics and other emergencies. What is clear is that national preparedness plans should address this issue of attendance at work explicitly, rather than adopt a "wait and see" approach. However attractive in the short term, the latter option could lead to chaos when disaster strikes, and undermine the success of the plans. 
ALEXANDER and WYNIA [13] examined the willingness of 1,000 senior US physicians to treat high-risk patients and their perceived preparedness for a bioterrorism incident. In total, $80 \%$ were willing to care for patients in an outbreak of an unknown but potentially lethal illness, $40 \%$ were willing to put themselves at risk of contracting a deadly illness to save others' lives and 33\% would care for infected smallpox patients even if not vaccinated. Despite $80 \%$ expressing a willingness to treat, only a fifth of respondents $(21 \%)$ felt prepared to deal with such an eventuality. Willingness to treat was associated with a belief in the professional duty to treat in epidemics, with feeling personally prepared, and being in primary care practice.

The difference between what physicians say they would do in a dramatic hypothetical situation and what they actually do in such situations remains to be seen, and the figures above also indicate that $20 \%$ would refuse to care for patients in an unknown, lethal outbreak; that is a fifth of the physician workforce. A similar result was obtained in a German study, where $28 \%$ of healthcare professionals surveyed at a University Hospital in Regensburg agreed that healthcare workers were professionally permitted to abandon their workplace to protect themselves or their family [14].

In a qualitative study of healthcare worker attitudes, Ives et al. [15] found that most staff felt a "duty to work", particularly practitioners covered by a code of practice, such as hospital doctors, nurses and general practitioners. Childcare, personal illness, and transport problems were identified as barriers to the ability to work; whereas barriers to the willingness to work were related to perceived risk to family or self, and choosing not to use alternative childcare options. About $60 \%$ of staff anticipated they were likely to work; doctors being more likely to work than nurses, ancillary workers and part-time workers. Obligation to colleagues was also noted as a factor: as REID [16] has pointed out, the risk refused by one individual is left to be absorbed by someone else, either within the healthcare team, or by society at large.

The study was based on the attitudes of a range of healthcare workers in a UK Midlands hospital. Social, cultural and religious variations across Europe may influence respondents' beliefs and views on their duty of care to patients.

\section{LESSONS FROM THE SARS EPIDEMICS}

In their aim to benefit patients with minimum harm, doctors and nurses also have a collective responsibility to learn from previous pandemics and emergencies.

YU et al. [17] investigated nosocomial spread of SARS by identifying superspreading events in hospitals in China and Hong Kong. A superspreading event is defined as three or more cases on a ward 2-10 days after admission of the index patient, or as the development of three or more cases within an 8 -day period on a ward with no identifiable source of SARS. Around $70 \%$ of infections were attributable to superspreading events, and multiple regression analysis showed the following explanatory factors: 1) patient received oxygen therapy; 2) patient received noninvasive ventilation (NIV); 3) resuscitation was performed on the ward; 4) staff members worked while experiencing symptoms; 5) minimum distance between beds of $<1 \mathrm{~m}$; and 6 ) lack of washing or changing facilities for staff. All these factors are highly relevant to staff education, ward layout, patient location and the therapies selected.

Analysis of transmission rates among hospital staff in the Toronto outbreaks revealed a greater risk of developing SARS in doctors and nurses performing endotracheal intubation and providing NIV, although for NIV use this did not reach significance [18].

NIV is an interesting case in point, as recommendations for use in guidelines are currently inconsistent $[19,20]$. In some SARS case series, early use of continuous positive airway pressure (CPAP) therapy or NIV was associated with lower risk of intubation and mortality [21-23] and no infection/seroconversion in staff, but there have been no randomised studies. NIV/ CPAP can be delivered in a high-dependency or respiratory ward area, thus offloading intensive care beds, and may be valuable in individuals with exacerbations of chronic obstructive pulmonary disease or heart failure. Benefits, however, should be set against the potential increased risk of droplet dissemination with infection transmitted to healthcare workers and other patients. In a pandemic that is relatively mild in normal individuals but produces ventilatory decompensation in those with chronic conditions, the balance tips towards providing NIV; if the pandemic is associated with high mortality, the balance moves away from NIV use unless strict safety measures for healthcare workers are effective. Currently, the UK Department of Health advises NIV/CPAP use in units experienced in NIV, with optimal infection control measures $[20,24]$. Readers should consult their own local and national guidelines.

Notably, healthcare workers in the USA exposed to SARSinfected patients did not contract the disease [25]. PARK et al. [25] speculate that the lack of transmission in this sample may be related to low prevalence of high-risk procedures, high-risk (superspreader) patients, or both.

The key learning points from the SARS epidemics [26, 27], particularly those concerning infection control, are summarised in table 1.

\section{ETHICAL PRINCIPLES}

The "Four Principles" approach to medical ethics was developed in the 1970s in the USA [28]. This highly influential approach revolves around the application and interpretation of four basic moral principles. The principles, which are neither hierarchically ordered nor absolutely binding, are "respect for autonomy" (obligation to respect the self-determination of moral agents), "beneficence" (obligation to benefit), "nonmaleficence" (obligation not to cause net harm), and "justice" (obligation to act fairly).

In the pandemic context, a Four Principles analysis would yield a number of obligations on the part of the clinician, each falling within one of the aforementioned broad principles, as follows.

\section{Beneficence}

1) Duty of care to patients; 2) responsibility to support the hospital, colleagues, profession and society; 3) duty to act in the best interests of relatives and loved ones; and 4) duty to be 


\begin{tabular}{|c|c|}
\hline TABLE 1 & $\begin{array}{l}\text { Lessons learnt from severe acute respiratory } \\
\text { syndrome (SARS) outbreak }\end{array}$ \\
\hline $\begin{array}{l}\text { Transmissio } \\
\text { Lack of inf } \\
\text { Inconsister } \\
\text { Having }<2 \\
\text { Carrying o } \\
\text { use of fit } \\
\text { A job as nc } \\
\text { No healthc } \\
\text { high-effic } \\
\text { handwas } \\
\text { procedu }\end{array}$ & $\begin{array}{l}\text { of SARS to healthcare workers was associated with: } \\
\text { tion control precautions } \\
\text { use of PPE } \\
\text { of infection control training } \\
\text { procedures producing aerosolised particles without required } \\
\text { ested high-efficiency mask (FFP2/3) or equivalent } \\
\text { medical support staff } \\
\text { e worker became infected with SARS if they used gloves, gown, } \\
\text { incy mask (equivalent to FFP2 mask) or surgical mask and did } \\
\text { ing, versus } 100 \% \text { of those who omitted more than one of these } \\
\text { S }\end{array}$ \\
\hline
\end{tabular}

reasonably informed about prevention, treatment, management and other relevant aspects of pandemic flu.

\section{Non-maleficence}

1) Obligation to minimise risk to patients, other staff members, family, society and oneself (e.g. not going to work when sick and of limited use, not deviating from standard operating procedures when performing invasive procedures); and 2) obligation to prevent further spread of disease by sound infection control and other appropriate measures. Also, healthcare workers must be aware that a refusal to treat patients may lead to loss of trust in medical professionals, loss of status and other professional harms.

\section{Respect for autonomy}

Obligation to respect the autonomous decisions of stakeholders and their evaluations of risks and benefits.

\section{Justice}

1) Fair treatment of medical staff, patients, colleagues, relatives, hospital and society, including in situations where resources are limited; 2) as far as is possible in the circumstances, respect for human rights of all involved; and 3) obligation to act within terms of the employment contract.

Of course, these many nonabsolute obligations may conflict with one another, and judgement should then be used to balance the competing duties. One obligation may be trumped by more compelling obligations. A family member may ask that one of the few ventilators go to their terminally ill relative when many others would derive much greater benefit from ventilation. Here, beneficence to other patients and a justice obligation to use limited resources in the most effective manner may trump respecting the autonomous request of the family member.

Other stakeholders, such as the hospital, the state and even patients, have reciprocal obligations which can also be categorised under these principles, such as the hospital administration's obligation to minimise risk to its healthcare staff (e.g. by providing protective equipment and training) and to treat staff in a fair and morally just manner. Infected patients also have obligations to minimise the risk of infecting others, such as covering their mouth and nose when coughing or sneezing, and observing quarantine advice.

During major catastrophes, the duty of care of the health service changes to a different mode than in normal circumstances. The service may be stretched beyond capacity and hard decisions will have to be made. Who will get vaccinated first? Who will be treated first? Which medical services should be first to shut down? Should clinicians and vital figures in society be prioritised? How can we avoid social unrest? The answers to these uncomfortable questions should be morally defensible and transparent. Further, they must be deemed acceptable by the various stakeholders, including members of the public who will constitute future patients and relatives. This is supported by all four principles, not least the principles of doing good and not causing net harm as any feeling of injustice will increase the likelihood of social unrest ("why should my child be left to die when this child gets treated?") which may jeopardise even the most elaborate plan. The Canadian consensus-based triage guidelines for intensive care admission are the most widely advocated for case prioritisation [27]. These consist of a scoring system of acute illness / organ failure combined with an assessment of chronic health and, importantly, allow pandemic flu/SARS and nonrespiratory pandemic cases to be considered. The rationale for this triage system is well rehearsed elsewhere [29-31].

Prompted by the SARS experience, SINGER et al. [32] have identified key ethical values relevant to all parties in a pandemic, and, more recently, other ethical frameworks have followed to assist the coordinated response to a pandemic [33]. The frameworks share many similarities (table 2). The obvious problem with these noble principles is that they do not translate into specific action-guiding practice. However, it is up to national bodies to translate the abstract ethical principles into concrete actions consistent with local resources, values and circumstances. It is naive to think that a universal, practical algorithm can be derived from the principles.

\section{CRUCIAL ROLE OF OTHER HEALTHCARE TEAM MEMBERS}

Doctors and nurses rarely work in isolation, and most now work within multidisciplinary teams. Hospitals would not function without porters and cleaning, laundry, catering and management staff, and these nonclinical workers will also be at risk of harm. Existing articles on duty of care nonetheless devote scant attention to these staff members. Do such staff have an obligation to carry on working through a pandemic and what are the health service's obligations to them? While some of these individuals, such as domestic cleaners and porters, may be at high risk of exposure, they do not appear to have a professional and moral obligation to put themselves at such high levels of risk even if under a contractual obligation to the hospital or to a subcontracted agency. Unlike healthcare professionals, they do not possess codes of ethics urging them to make the care of patients their first concern. Pandemic planning teams must devote greater attention to these team members as their involvement is invaluable to any successful management plan.

\section{HUMAN WORKFORCE PLANS AND REGULATIONS}

In addition to staff absence due to personal infection, quarantine and caring duties, high stress levels may impact 


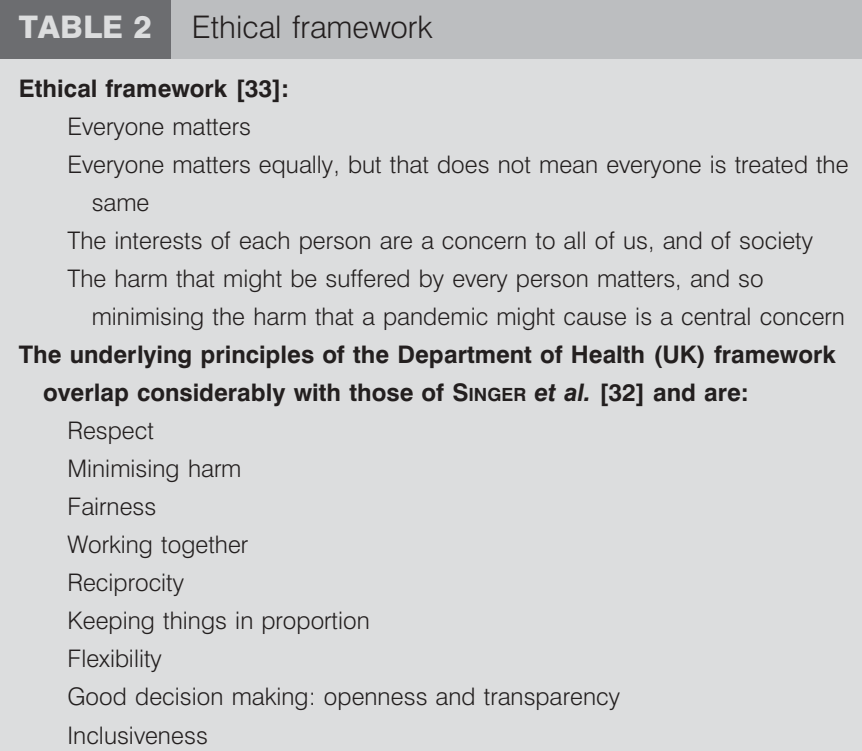

Part of this table is reproduced from [32] with permission from the publisher.

attendance, and some staff members may not report to work due to fear of getting infected or transmitting the virus to family members or friends.

Pre-pandemic planning in most European countries includes workforce mapping to identify those with additional transferrable skills, those with childcare commitments and likely gaps in service provision. As elective clinic and surgery will cease, staff will be redeployed and, if necessary, can be trained or work alongside experienced colleagues. Telephone consultations and telemedicine options may replace clinics and, patient confidentiality permitting, some work can be done from home. Other healthcare sources, such as retired medical staff and medical students may also be called upon for assistance under honorary contracts. Training rotations for postgraduate medical trainees may be frozen (i.e. trainees will remain in the same hospital) to simplify staff allocation, reduce spread of infection and decrease the training burden.

A modelling study [34] of the excess intensive care workload generated by pandemic flu in the Netherlands found that combining a range of measures could accommodate the expected surge in admissions based on an estimated $30 \%$ attack rate and both $25 \%$ and $50 \%$ ICU admission rates. These measures include increasing shifts from 8 to $12 \mathrm{~h}$, delegating nonspecific ICU tasks to non-ICU trained staff, and employing prophylactic antiviral therapy for healthcare workers. However, it is not clear whether this intensity of workload could be sustained for 12-15 weeks, or even a second wave of infection. In addition, the assumption of an average stay of 10.5 days and ICU mortality of $27 \%$ may be at variance with the clinical course in a pandemic, and use of prophylactic antiviral therapy in staff is not in accordance with current recommended practice.

The pandemic preparedness plan in the USA notes that the circumstances for which employees have a right to refuse to work are very limited [35]. An assignment can be refused only if: 1) the employee believes that doing such work would put them in serious and immediate danger; 2) they have asked their employer to remedy the hazard; 3 ) there is no time to call the Department of Labor's Occupational Safety and Health Administration, and 4) there is no other way to do the job safely. The employer can impose disciplinary action for refusing to work, although employees have the right to refuse to work if they believe in good faith that they are exposed to imminent danger.

In the study by IVES et al. [15], healthcare workers identified the need for more direction on what was expected of them. If asked to assume new tasks and responsibilities, they sought assurance that they would be provided with the appropriate skills and indemnity for working in these extended roles.

If staff fail to attend due to anxiety, some guidelines suggest that clinical colleagues should attempt to convince the nonattendees to attend by direct approach. The aim is to persuade rather than penalise, understand concerns and take into account views of staff side organisations. Although local disciplinary measures will remain in place, it is unlikely that such measures will be taken during a pandemic.

As misunderstandings and disproportionate fear are common during epidemics, communication between stakeholders is key. Healthcare workers are understandably concerned by the lack of information [15] and education on personal protective gear and infection control. Staff will have to be reminded that only those in contact with patients are at risk and that if protected properly there should be no added risk of infecting their children or loved ones. Nonetheless, it is possible that many healthcare workers will use hospital accommodation during prolonged shifts to reduce fears of transmission at home.

\section{RECIPROCITY}

While staff have a duty to work unless there is significant risk of serious harm, the hospital has reciprocal duties to its employees. These duties include: 1) communication to staff on what is expected of them and how to minimise risk to themselves through appropriate infection control measures; 2) adequate support to enable staff to perform their duties; 3) adequate resources, including personal protective equipment; 4) skill training; 5) a safe environment; 6) accommodation; 7) means of communication between teams and for support, e.g. mobile phones and mobile e-mail devices; 8) medical advice, e.g. screening when attending for duty; 9) counselling and psychological support; 10) adequate security, e.g. for ambulance staff, those working in emergency room areas and dispensing oseltamivir; 11) provision of postexposure antiviral medication, if staff are exposed and fulfill criteria as contact; and 12) vaccination (it is not yet clear if frontline staff will receive preferential vaccination once a vaccine is available; this will probably be determined during the course of the pandemic, depending on various factors, such as the availability of the vaccine, the population most affected, and the lethality of the virus).

\section{ARE REWARDS ETHICAL?}

There has been little discussion on whether incentives or rewards should be offered to staff to encourage attendance. Although contractual obligations seemingly obviate the need 
for additional rewards, the UK Department of Health Human Resources guidance [17], for example, indicates "Trusts (hospitals) may wish to consider what incentives can be offered to staff to increase their hours." This may be particularly relevant to contract and temporary staff, such as domestic cleaners and catering staff. It is also possible that individual efforts will be recognised by professional mechanisms, such as national professional excellence awards.

Here again, history can provide valuable lessons. Some healthcare staff working during the SARS epidemics in Toronto were offered higher pay to compensate for their high-risk exposure. This created, as well as resolved, problems. Nurses who worked at institutions that did not pay extra felt a sense of injustice: their colleagues a few miles away were paid more for similarly dangerous work. Under the current guidance, this situation may repeat itself as it is up to individual hospitals to offer incentives. Discrepancies in pay which are deemed unfair by healthcare workers may lead staff to feel undervalued and dissuade them from coming to work.

It may also undermine team cohesion and remove an important motive in discharging the duty of care during a pandemic: loyalty to team members and colleagues.

\section{CONCLUSIONS}

We have explored ethical aspects of the duty of care in pandemic flu and other emergency situations, both of staff towards patients and of the health service toward staff. We have also pointed out the crucial need, in pandemic preparedness plans, to look beyond doctors and nurses to auxiliary staff such as porters, cleaners and caterers. It is evident that actual risk and perception of risk will vary according to the virulence and infectivity of the virus. Timely, accurate and honest dissemination of information to healthcare teams, to enable risk to be assessed, is paramount. It is difficult to avoid the conclusion that medical and nursing staff at least will be expected to work unless they are ill or have dependant care responsibilities. It remains to be seen how this duty is discharged if, for example, personal protective equipment runs out, staffing is totally decimated, or the virus mutates into a particular virulent and infectious form. If truth be told, in chaotic and desperate situations, ethics are secondary. Selfpreservation takes over. Though different from pandemic flu in several respects, the recent history of Ebola haemorrhagic fever in Africa, where traumatised healthcare professionals and relatives abandoned their dying patients in hospitals, is a sobering reminder of this [36].

Of relevance is the outcome of the inquest of the Hong Kong Coroner's Court into the six healthcare professionals who died of SARS. The coroner returned a verdict of natural causes. Although Tuen Mun Hospital in Hong Kong had no shortage of supplies, medical staff were given one mask per 10-h shift, had to turn gowns inside out and hang them up when on breaks, and were expected to clean and re-use goggles [37]. We all have a duty to learn from these experiences, both positive and negative, and to educate ourselves through training courses, assimilating experience from the H1N1 swine flu outbreak and by reading relevant website updates and literature. Such are the demands of the principles of beneficence and non-maleficence. As a profession, it seems wise, given the spectrum of severity of pandemic flu, to hope for the best, plan for the worst and brace ourselves for a mighty challenge.

\section{FURTHER INFORMATION AND WEBSITES}

WHO information and resources: www.who.int/csr/disease/ influenza/pandemic/en/

US government information: www.pandemicflu.gov

Centers for Disease Control and Prevention: www.cdc.gov/ flu/Pandemic/

UK government: www.dh.gov.uk/en/Publichealth/Flu/ PandemicFlu/index.htm

Pandemic flu: clinical management of patients with an influenza-like illness during an influenza pandemic. Provisional guidelines from the British Infection Society, British Thoracic Society, and Health Protection Agency in collaboration with the Department of Health. Thorax 2007; 62: Suppl. 1, 1-46.

\section{STATEMENT OF INTEREST}

None declared.

\section{REFERENCES}

1 Beigel JH, Farrar J, Han AM, et al. Avian influenza A (H5N1) infection in humans. N Engl J Med 2005; 353: 1374-1385.

2 Mounier-Jack S, Coker RJ. How prepared is Europe for pandemic influenza? Analysis of national plans. Lancet 2006; 367: 1405-1411.

3 Mounier-Jack S, Jas R, Coker R. Progress and shortcomings in European national strategic plans for pandemic influenza. Bull World Health Organ 2007; 85: 923-929.

4 World Health Organization. Consensus Document on the Epidemiology of Severe Acute Respiratory Syndrome (SARS). Geneva, World Health Organization, 2003.

5 Wilson N, Thomson G, Mansoor O. Print media response to SARS in New Zealand. Emerg Infect Dis 2004; 10: 1461-1464.

6 Liddle R Swine flu about to kill us? Oh sure -, pigs can fly, The Sunday Times, May, 3: 2009.

7 UK Department of Health. Pandemic Flu: A National Framework for Responding to an Influenza Pandemic. London, Department of Health, 2007.

8 Ruderman C, Tracy CS, Bensimon CM, et al. On pandemics and duty to care: whose duty? who cares? BMC Med Ethics 2006; 7: E5.

9 General Medical Council. Good Medical Practice. Pandemic Influenza: Responsibilities of Doctors in a National Pandemic. London, General Medical Council, 2009.

10 American Medical Association. Physician Obligation in Disaster Preparedness and Response. Chicago, American Medical Association, 2004. Available from: www.ama-assn.org/apps/pf_new/ pf_online?f_n=browse\&doc $=$ policyfiles $/ \mathrm{HnE} / \mathrm{E}-9.067 . \mathrm{htm}$

11 UK Nursing and Midwifery Council. Duty of Care. London, Nursing and Midwifery Council, 2008.

12 Malm H, May T, Francis LP, et al. Ethics, pandemics and the duty to treat. Am J Bioethics 2008; 8: 4-19.

13 Alexander GC, Wynia MK. Ready and willing? Physicians' sense of preparedness for bioterrorism. Health Affairs 2003; 22: 189-197.

14 Ehrenstein B, Hanses F, Salzberger B. Influenza pandemic and professional duty: family or patients first? A survey of hospital employees. BMC Public Health 2006; 6: 311.

15 Ives J, Greenfield S, Parry JM, et al. Healthcare workers attitudes to working during pandemic influenza: a qualitative study. BMC Public Health 2009; 9: 56.

16 Reid L. Diminishing returns? Risk and the duty to care in the SARS epidemic. Bioethics 2005; 19: 348-361. 
$17 \mathrm{Yu}$ IT, Xie Z, Tsoi K. Why did outbreaks of severe acute respiratory syndrome occur in some hospital wards and not others? Clin Infect Dis 2007; 44: 1017-1025.

18 Fowler RA, Guest CB, Lapinsky SE, et al. Transmission of severe acute respiratory syndrome during intubation and mechanical ventilation. Am J Respir Crit Care Med 2004; 169: 1198-1202.

19 World Health Organization. Clinical Management of human infection with influenza A (H5N1) virus (advice update August 15, 2007). Geneva, World Health Organization, 2007.

20 UK Department of Health. Pandemic Influenza: Surge Capacity and Prioritisation in Health Services. London, Department of Health, 2008.

21 Zhao Z, Zhang F, Xu M, et al. Description and clinical treatment of an early outbreak of severe acute respiratory syndrome (SARS) in Guangzhou, PR China. J Med Microbiol 2003; 52: 715-720.

22 Cheung TMT, Yam LYC, So LKY, et al. Effectiveness of noninasive positive pressure ventilation in the treatment of acute respiratory failure in severe acute respiratory syndrome. Chest 2004; 126 : 845-850.

23 Yam LYC, Chan AYF, Cheung TMT, et al. Non invasive versus invasive mechanical ventilation for respiratory failure in severe acute respiratory syndrome. Chin Med J 2005; 118: 1413-1421.

24 UK Department of Health. Pandemic Influenza: Guidance for Infection Control in Critical Care. London, Department of Health, 2008.

25 Park BJ, Peck AJ, Kuehnert MJ, et al. Lack of SARS transmission among healthcare workers, United States. Emerg Infect Dis 2004; 10: 244-248.

26 Lau JTF, Fung KS, Wong TW, et al. SARS transmission among hospital workers in Hong Kong. Emerg Infect Dis 2004; 10: 280-286.
27 Seto WH, Tsang D, Yung RW, et al. Effectiveness of precautions against droplets and contact in prevention of nosocomial transmission of severe acute respiratory syndrome (SARS) Lancet 2003; 361: 1519-1520.

28 Beauchamp T, Childress J. Principles of Biomedical Ethics. Oxford, Oxford University Press, 2000

29 Christian MD, Hawryluck L, Wax RS, et al. Development of a triage protocol for critical care during an influenza pandemic. CMAJ 2006; 175: 1377-1381.

30 Melnychuk RM, Kenny NP. Pandemic triage: the ethical challenge. CMAJ 2006; 175: 1393-1394.

31 Upshur REG, Faith K, Gibson JL, et al. Stand On Guard For Thee: Ethical Considerations in Preparedness Planning for Pandemic Influenza. Toronto, University of Toronto Joint Centre for Bioethics Pandemic Influenza Working Group, 2005.

32 Singer PA, Benatar SR, Bernstein M, et al. Ethics and SARS: lessons from Toronto. BMJ 2003; 327: 1342-1344.

33 UK Department of Health. Responding to Pandemic Influenza the Ethical Framework for Policy and Planning. London, Department of Health, 2007.

34 Nap RE, Andriessen MPHM, Meesen NEL, et al. Pandemic influenza and excess intensive-care workload. Emerg Infect Dis 2008; 14: 1518-1525.

35 USA Government. Avian and Pandemic Flu Information. www. pandemicflu.gov/index.html Date last accessed: March 14, 2009. Date last updated: May 28, 2009.

36 Sokol D. From anonymity to notoriety; a history of Ebola haemorrhagic fever. MSc Thesis, Oxford University, Oxford, UK, 2002.

37 Parry J. Coroner criticised over conduct of SARS inquest. BMJ 2004; 329: 1204. 